\title{
Research on Entrepreneurship Education Reform in Universities under the Background of Public Entrepreneurship
}

\author{
Junzheng $\mathrm{Wu}^{1, \mathrm{a}}$ \\ ${ }^{1}$ Xi'an Peihua University, Xi'an, Shaanxi, China, 710125 \\ ${ }^{a}$ email
}

Keywords: Entrepreneurship Education, Public Entrepreneurship

\begin{abstract}
The reform of entrepreneurship education is the necessary choice under the background of public entrepreneurship. As the talent training bases, universities should undertake the entrepreneurship education reform mission to train the complex talents in the new era. However, there are many problems in the entrepreneurship education in universities, such as backward concept, incomplete content and single model of entrepreneurship education. This paper analyses the above problems, and gives the corresponding countermeasures to provide some references for the university teachers.
\end{abstract}

\section{Era Background of Public Entrepreneurship}

The employment situation of the current society is becoming more and more serious. The economic reform has already entered the deep water area in China. The problems of how to solve the difficult problem of employment of the current society and how to inject new vitality into the economic development have become lasting social problems. The difficult employment slows economic development in such a large background. Premier Li Keqiang put forward the idea of "public entrepreneurship and innovation" for the first time in the summer Davos forum in 2014. The concept caused widespread concern in the community. In the follow-up process to implement, the government introduced a series of related policies, the central government has put forward innovation and public entrepreneurship peoples call, hope to innovation and entrepreneurship to promote the sustainable development of the economy of our country. At present, it is necessary to enable economic growth to overcome the downward pressure, we must change the objects and the way of economic development, the development and utilization of those storage rich and relatively insufficient development of unconventional resources which the most important is national creative resources, including the development of every member of society and social organizations, each kind of social relations and social life contained in the creative potential, this potential for change in national creative work for leading the advanced productive forces. Colleges and universities have a relatively complete hardware facilities, with the advantages of science and technology resources, college students is one of the most innovative and entrepreneurial potential of the group. They have passion, ideas, and the teacher's guidance and school support, with the realization of the natural advantages of innovation and entrepreneurship. As the training of high - quality, high - skilled, application-oriented talents bases, the universities should undertake the historical mission. Therefore, it is a good way to improve the overall level of entrepreneurship education in universities as a breakthrough point. 


\section{Current Situation of Entrepreneurship Education in Universities}

Regrettably, there are many problems in the entrepreneurship education of higher education in our country. The problems are:

Backward Concept of Entrepreneurship Education. Although entrepreneurship education has been launched in the country, but compared to the huge base of our university students, the proportion of the number of people to participate in innovation and entrepreneurship is still low. Also, subject to the restriction of funds, manpower and other aspects, many colleges and universities pay more attention to support for molding enterprise culture and individual key projects, ignoring the majority of students ability training of college teachers did not establish the concept of modern education, is still used in the traditional form of education, the teaching process has not been integrated into awareness of entrepreneurship education, education for the students more alike, contrary to the principle of individuation and diversification of entrepreneurship education. At the same time, as the intellectuals, college students and teachers only school to carry out the entrepreneurship education regarded as a part of quality education, attention degree is not high and the wishes of the individual is not strong, entrepreneurial enthusiasm is also insufficient. Due to the economic and social development of the times, colleges and universities in the employment oriented guidance, has always been more emphasis on the students theoretical knowledge, professional skills and academic ability of the training. Restricted by the existing teaching system, the structure of teachers and the traditional personnel training mode. The entrepreneurship education can not cover the whole process of life. And the status of entrepreneurship education is not high in the whole teaching system.

Incomplete Content of Entrepreneurship Education. Universities carry out entrepreneurship education like a ranging fire, but students after graduation self employment rate fail to significantly improve. Some are even in the school winning entrepreneurial projects ultimately unable to take root, the reason is entrepreneurship education mostly from books and teachers' subjective intention, and not the real needs of the society. Moreover, the information society is changing thousands of classes, the knowledge is likely to go to graduate school is outdated, resulting in theory can not be applied to the actual, and even may be counterproductive. Especially now, some colleges and universities because of the lack of teachers, to treat entrepreneurship this discipline that as long as teachers in general are capable of, many teachers of all no actual entrepreneurial experience, only empty talk, give students reference is greatly reduced. Entrepreneurship education has the multidisciplinary characteristics, is a highly integrated and practical education, requests the teacher has broad knowledge. At the same time, and the need to have rich social experience and practice experience, however, at this stage of China's entrepreneurship teachers most are part-time teachers bear the responsibility, in quantity and knowledge structure meet the entrepreneurship education for multi discipline structure requirements in addition, due to the lack of practice experience, most of the teachers in the student meet business practical problems. It is difficult to for students provide powerful help and guidance.

Single Model of Entrepreneurship Education. Entrepreneurship Education in universities need to increase the proportion of various forms of education in entrepreneurship courses, such as entrepreneurship training, business simulation, practice experience, change the traditional teaching mode. But there are only a few schools can do, a lot of local colleges and universities of entrepreneurship education or to the "classroom teaching" as the core model, supplemented by other activities. These courses lack of students' active participation and entrepreneurial practice, can not effectively play the initiative of students, enthusiasm and innovation, thus affecting the effectiveness of entrepreneurship education. Due to the lack of systematic evaluation system, 
making some entrepreneurial projects of college students in the process of recommendation, whether to achieve the corresponding market access conditions, it is difficult to quickly and accurately assessed. Another difficult situation for college students to start a business is no venture capital, most of the students venture capital from my family and friends, together with the social financing channels is not perfect, venture capital source less and scattered. And for students in the beginning of the community, there is no doubt that there is a big risk, because they are mostly in school, not only do not have the support of venture capital, there is no practical experience in the community to get. Now many schools have developed policy entrepreneurship, the school will be in the process of students' entrepreneurship given to entrepreneurship scholars some venture capital. But only these apparently not enough. The students in the actual business process aslo lacked the venture capital funds.

\section{Reform Suggestions on Entrepreneurship Education under the Background of Public Entrepreneurship}

Update Concept of Entrepreneurship Education. The main purpose of entrepreneurship education in Colleges and universities is to cultivate college students' sense of entrepreneurship, entrepreneurial quality and ability, so that they can seize the opportunity to succeed when the time is ripe. Therefore, entrepreneurship education in Colleges and universities must be clear. The training students with basic awareness of entrepreneurship, entrepreneurship and entrepreneurial aspects of goal, to cultivate college students independent learning and the ability to work and strong social adaptability, from bud enhance university students' innovative undertaking. The possibility of the implementation of educational content. Universities to improve the awareness of entrepreneurship education, not only their own development, social development, the need for personal development of students, but also the need to actively promote the reform of teaching and education in universities. In the process of world economic development, new industries, new products, new business models in the rapid growth, innovation and ability to improve, innovation on the economic development of a country's contribution rate is more significant. As the basic force to promote the progress of science and technology, colleges and universities must have a profound understanding of the important mission of their own. Secondly, implementation of entrepreneurship education is to deepen the understanding of the essence of education, is for talent cultivation, quality of workers to enhance the rule of deepening understanding, disadvantages to get rid of the traditional model of personnel training, to promote and guide our country university personnel training quality of stride a new step. University is the main position of innovation and entrepreneurship shall conform to the times development. Univeristies must shoulder the historical trust and truly establish the new entrepreneurship education concept system in the public entrepreneurship and innovation backgrond.

Improve Content of Entrepreneurship Education. Curriculum system is the comprehensive embodiment of talents training objectives, including teh teaching, curriculum design, teaching materials, teaching methods and teaching management mode. Curriculum system, to a certain extent, determines the university students' knowledge structure and ability structure, and reasonable curriculum system is the guarantee for the realization of the goal. The practice of entrepreneurship education is very strong. It not only requires students to master the theoretical knowledge, but also have practice experience, in practice to the interconnect. Therefore, the curriculum system of entrepreneurship education for college students to including teaching and practice of the two pieces, entrepreneurship education should be the combination of theory and practice, and to the two blocks combined with sophisticated, in order to achieve the goal of entrepreneurship education, improve 
students entrepreneurial ability to strengthen the college students' education system and the. Curriculum system should be included in the theory teaching, case teaching, simulation practice, field survey of four modules, internal to fully mobilize students' enthusiasm, external and government, regional social extensive cooperation, colleges and universities should bring their own scientific research society, serving the society and the development of regional economy, innovative enterprises and Entrepreneurship education for college students live material. To establish the system of the science, the University of innovation and entrepreneurship, and not only through the opened a couple of entrepreneurship courses even entrepreneurship education, can only say that entrepreneurship curriculum is the core of the theory of entrepreneurial learning and skills training part. Perfect curriculum system of entrepreneurship education needs to be combined with different business objects to achieve matching design of entrepreneurship courses; on the other hand, we need achieve the integrity of business knowledge according to the general requirements of entrepreneurship education.

Enrich Models of Entrepreneurship Education. Entrepreneurship education need combine the theory and practice. We can pass by the appointed special guidance teachers or mentors of college students entrepreneurial activity throughout the guide, and guide the teacher can not just appointed, and must is to have practical experience in business teacher, it is entirely possible to society to hire some successful entrepreneurial part-time teacher as a guide for students. And students will be divided into a number of teams, to experience the whole process of entrepreneurship, planning, financing, implementation, and so on. Various team members through real social practice to experience the various difficulties and risks of entrepreneurship, to grasp the opportunity to work in the future to prepare. The reform of teaching methods will be based on the traditional teaching methods, such as teaching, lectures, and so on, which can be changed into practical methods such as case analysis, business plan simulation, project incubation and so on. By strengthening the construction of the practice teaching resources and sharing, widely built a practice training platform, innovation and entrepreneurial activity center, established venture capital fund, to train students entrepreneurial team, to further improve the students to start the whole process service. Finally, in order to achieve coverage from extension. From the public opinion environment, the training mechanism, the internal management and so on, the reform of the student management rules and regulations, and improve the students' individual growth, innovative talents training system. We can construct the business credit accumulation and transfer system or suspension entrepreneurial system to create more relaxed entrepreneurship environment.

\section{Conclusion}

Public entrepreneurship is the necessary requirements of China's social development and economic transformation under the new normal. Under such a background, the entrepreneurship education in universities is expected to boost the economy. The correct reforms of the entrepreneurship education not only can provide many jobs to the gradutate studetns, but also can promote the steady development of China's economy.

\section{References}

[1] Chen Chi, Education Exploration, Vol. 25 (2015) No 10, p.91-94

[2] Jin Yanli, He Yunfeng, Social Sciences Journal of Universities in Shanxi, Vol. 27 (2015) No 7, p.69-72 
[3] Dong Wei, Education and Vocation, Vol. 99 (2015) No 35, p.87-89

[4] Liu Wei, The Guide of Science \& Education, Vol. 6 (2015) No 11, p.162-163

[5] Cao Yang, Zhou Yunlong, Journal of Northeast Normal University (Philosophy and Social Sciences), Vol. 64 (2014) No 2, p.200-202 